he will have completed his mathematical calculations in order to give the exact height. Barometric pressure and triangular measurements from twelve differen points were taken. In scaling the mountain Dr. Cook realized a life am',ition, and besides obtained geographical information about a country of which very little is known.

\section{TOTAL ECLIPSE OF THE SUN IN JANUARY, 1907,}

\section{Proctor}

"Eclipses are predicted, and science bows them in." The next total eclipse of the sun takes place on January 13, 1907, and will be visible in central Asia. The track of the eclipse is wholly on land, and gives the last favorable opportunity for observing an eclipse until that of April 17, 1912, which may be witnessed for one minute in South America, and for a brief in terval in Spain.

The best region for observing the 1907 eclipse is available by means of railways recently constructed in Russian territory. On this railway, and about twothirds of the way from Tashkend to Samarkand, lies Jizak, only a few miles from the exact line of central eclipse. Fortunately, the railroad from Orenburg to Tashkend, practically a branch of the Trans-Siberian Railway, which has been in course of construction, is now completed. Other easily accessible places near min, Nau, and Ura-Tiube. The last is practically cenmin,

From the United States, the best way to reach Jizak is by means of Naples, Constantinople, the Black Sea, Tifiis, the Caspian Sea, Bokhara, and Samarkand. From Krasnowovsk on the Caspian Sea to Tashkend trains run regularly, there being two trains which leave Krasnowovsk daily at $5 \mathrm{~A}$. M. and 7:15 P. M. respectively.

If we go farther east, the track of the eclipse leads into a region more and more difficult of access, although the totality lasts a few seconds longer, and the eclipsed sun is a few degrees higher. Only one station in Mongolia, Tsair-osu, seems likely to be considered. Ir The American Journal of Science, for March, 1906, Prof. David P. Todd, of Amherst Observatory, has given the position of ten possible observing stations, exact local times of the four phases, durations of totality, and other interesting facts.

As shown by the map (taken from the Nautical Almanac for the year 1907) the midale of the eclipse occurs at sunrise in a region north of the Black Sea, the track crossing the Caspian Sea, where the eclipse begins at sunrise. It reaches Jizak in Turkestan about a quarter to nine, totality beginning at $9 \mathrm{~h} .59 \mathrm{~m}$. 58.4 sec., and ending at $10 \mathrm{~h} .1 \mathrm{~m}$. 55.2 sec., the duration being about two minutes. Jizak is thirteen miles south of the central line, while Ura-Tiube is only two miles south, and practically central. There the eclipse begirs at 8 h. 50 m. 52 sec., totality being at $10 \mathrm{~h}$. $6 \mathrm{~m} .37 .1$ sec., and ending at $10 \mathrm{~h} .8 \mathrm{~m}$. 40.9 sec., a duration of two minutes and seventeen seconds.

At Tsair-osu in Mongolia, which is two miles north of the central line, the eclipse begins at $12 \mathrm{~h} .29 \mathrm{~m}$. 58 sec., with totality at 1 h. $49 \mathrm{~m}$. 41.6 sec., and ends at $1 \mathrm{~h} .51 \mathrm{~m}$. $36.7 \mathrm{sec}$, a duration of about one minute and fiifty-five seconds.

It appears that no expedition from any of the well known American astronomical institutions will observe the eclipse, and in all probability no eclipse expeditions from Europe will attend, on account of such unfavorable weather conditions liable to prevail, and uncertain commurfication with the difficult region (Russian Turkestan).

The following eclipse will be that of January 3 1908, and will be wholly confined to the Pacific Ocean, with the possibility of observing stations on tw islands. A brief account of these islands will show how little they are adapted for such work. One named Flint Island, one of the Line group, is situated west of the Marquesas Islands, in long. $151 \mathrm{deg} .48 \mathrm{~min}$. W. and lat. $11 \mathrm{deg}$. $26 \mathrm{~min}$. S. It belongs to the British, and was discovered in 1801. It is covered with brush wood and trees, and is visible from the masthead of a ship from a distance of sixteen miles.

This litt.e island is about $2 \frac{1}{2}$ miles long N.N.W. and $1 / 2$ mile broad S.S.E., and is fringed by a steep coral reef which dries at low water, and extends seaward quite a distance. In the interior of the island are two small lagoons of brackish water. Not a very promising prospect for the most enterprising observer despite the fact that the duration of totality will be four minutes, and the sun's altitude will be $74 \mathrm{deg}$.

In 1880 the island was uninhabited, and the buoys formerly in use were gone. There is no rise and fall of tide, and the landing is said to be very bad, even for surfboats. These interesting facts are to be found in the Monthly Notices of the Royal Astronomical Society for March, 1906, and were contributed by Dr. A. M. W. Downing, F.R.S. He gives a still less favorable report of Hull Island. This island is situated halfway between the Marquesas Islands and Solomon Islands, in long. 172 deg. $13 \mathrm{~min}$. W. and lat. 4 eg. $30 \mathrm{~min}$. S. Hull Island, one of the Phoenix group, belongs to the British, and was discovered and so named by Wilkes in 1840 . It has a lagoon and a little fresh water, and there are some cocoanut trees on it, about 50 feet high. A coral reef fringes the island, and landing is difficult except by entering the lagoon by means of the boat passages on the northwest side. There is no anchorage. In 1899 the island was uninhabited.

The winds are almost constantly from the eastward, but squalls accompanied by light rain occur in the neighborhood all the year round. The wind is variable from January to May, during which period bad weather is most common. Small chance there is there of observing the eclipse with any success, since it occurs on January 3 , and totality only lasts $2 \mathrm{~m}$. 51 sec. The sun's altitude will be $43 \mathrm{deg}$

Both these islands have been leased to Lever's Pacific Plantation Company, and intending observers are requested to communicate with the officers of this company, situated at Port Sunlight, Cheshire. Such is the irony of fate, permitting one of the grandest sights the eye of mortal can ever behold to waste its glory on these almost inaccessible islands! On December 23, 1908, another eclipse track will cross the South Atlantic Ocean, and on June 17, 1909, an eclipse will occur in the neighborhood of Greenland.

The South Antarctic regions will be crossed by an eclipse track May 9, 1910, and another will visit Aus. tralia, May 28, 1911. On all these occasions, since the eclipse tracks lie almost wholly across oceans, or in inaccessible parts of our globe, no observations of value can be made. This is due to the fact that no device for securing accurate astronomical observations from the deck of a ship has yet been perfected, while to reach the inaccessible regions tedious and expensive expeditions are necessary.

At a meeting of the British Astronomical Associ ion which met at Sion College, Victoria Embankment, on June 20 last, Mr. W. T. Lynn, one of the members, read a paper on the total eclipse of January 13, 1907

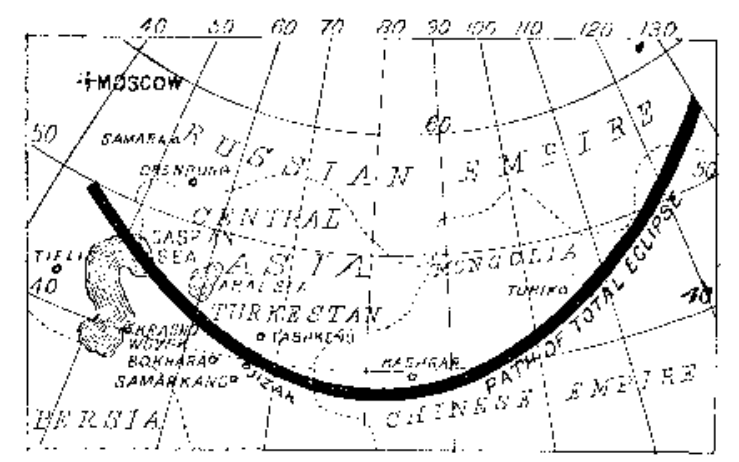

PATH OF THE ECLIPSE OF THE SUN, JANUARY, 1907.

In it he referred to the fact that "the Russian government has recently established an observatory at Tashkend, nearly due north of Samarkand, and no doubt the astronomers there will observe the total eclipse at the second catalogue of stars ever made was fact that the second catalogue of stars ever made wa Beg, the grandson of Tamerlane, built at Samarkan the greatest astronomical observatory in the world, one hundred and forty years before Tycho Brah erected Uraniborg in Denmark.

After Mr. Lynn read his interesting paper, Mr. A. C. D. Crommelin, the president of the Association, $r$ marked that "unfortunately the next eclipse is one that only those should venture to go to see who are prepared to brave an Arctic degree of cold. As general rule, they regarded an eclipse as a favorable one when its track is mostly over land, and as an unfavorable one when its track is mostly over water The track of the eclipse of next January is entirely over land except for a few of the lakes of central Asia and yet it is a very inaccessible eclipse, for it is ove Tibet and Siberia in the depths of winter, and he i afraid the cold there will be very severe indeed." The president, however, called particular attention to th total eclipse of January 3, 1908, and hoped that some of the members of the association would be represented at this, although the journey would be a long one.

Is it any wonder, when we realize that although total eclipse occurs every year from 1907 to 1912, and that none are easy to observe between those dates, that no effort has been made to observe the total eclipse of January 13, 1907, at one at least of the te possible stations whose positions have been so care fully computed by Prof. David P. Todd.

Inasmuch as there is a difference between the civil and the astronomical day, some confusion may arise from the eclipse will occur. The astronomical day begins at noon; the civil day at midnight, twelve hours earlier. Hence according to the one system the eclipse will occur on January 13 , and according to the other on January 14.

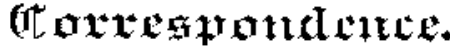

\section{Alcohol from Cacti. \\ 'To the Editor of the Scientific American:}

The profitable manufacture of denatured alcohol from cacti has been found to be feasible by G. A. Burns, chemist, manager of the Southern Pacific Hospital, San Francisco, prior to the fire, who is now in Los Angeles. Mr. Burns declares that much desert land in California and New Mexico can be reclaimed by the growing of cactus, the manufacture of alcoho from the plant, and the use of the alcohol as fuel for power plants to pump water for irrigating. $\mathrm{Mr}$. experiments that denatured alcohol can be produced in sufficient quantities from the common desert treeso monotonous to the tired eyes of the tourist coming from the East-to furnish heat, light, and power for all general farming purposes. From five pounds of pulp he distilled, in a crude way, more than a gallon of alcohol, which was clear in color and burned readily with a very bright, warm glow.

The product contains four times as much energy as wood alcohol. He believes it can be produced cheaply, and that five acres planted to cacti would be large enough "power plant" to run a farm of 160 acres. The plants could be cut down, ground up by special machinery, and put through the process of fermentation and distillation like corn, wheat, or barley. The surplus steam escaping from a stationary engine on the farm could be utilized in the process of distillation. The Nevada cactus grows from two to five feet high and with great rapidity, or about as fast as corn in Kansas. This being the case, it would soon grow up from the stubble or stump, and in about six or eight months would again be ready to produce nontaxable alcohol for commercial purposes.

Mr. Burns first got his idea of the possibilities of the commercial value of the cactus from Mexico, where it is well known that the natives make a very potent liquor from cactus.

Cactus alcohol could be produced more cheaply than wood alcohol, besides being four times as powerful. The raw material too would be right on the farm.

The plan could be adapted readily to the valley of Las Vegas. It is fifty miles long and on an aver age thirty miles wide. It is of a sandy loam, very fertile and very level, and with only a trace

"Everything," said Mr. Burns, "that California produces, with the possible exception of oranges, can be grown in this valley. Water can be had at from ten to twenty feet, and with cheap fuel to pump it to the surface, such as I am convinced can and will be obtained from the cactus, Las Vegas will become a little Eden."

AlLie Alger.

$$
\text { Sawtelle, Cal. }
$$

A Plea for the Preservation of the Salton Sea. To the Editor of the ScIentific AMERICAN:

Conditions and circumstances connected with the flow of the Colorado River into what is known as the Salton Sink have occasioned considerable comment in various publications; and since the strenuous efforts of government and railroad engineers to divert the river back into its original channel have succeeded, it has been advocated that means should be taken to retain the new sea in approximately. its present dimensions, the argument being advanced that evapora. tion from this new body of water has caused rains the past season in sections of the Southwest where like precipitation has been almost wholly if not entirely unknown before. In opposition to this it is contended that the unusual rains have been merely coincident, without being caused either directly or indirectly by the new lake.

When considered with more than passing notice, and contemplated from the standpoint that from a seem. ingly not greatly important incident might come resuits of unthought-of beneficent effect to a very great part of the whole country, and when such effect really seems developing, then the matter becomes an interesting one, and is apt to attract the attention of anyone who looks forward to future eventualities, as well as to the first visible results. I am of the opinion that those who contend for the permanent retention of the Salton Sea are correct in their conclusions that the new sea has caused and indicates a decided modification in climate; and the unusual rains in the West and Southwest, especially in the latter section, the past season may only have been an indication of what is to continue through other seasons of the year-as instance the recent unprecedented storms in the Southwest. Also I anticipate that if the Salton Sea is retained, climatic conditions in the West and Southwest will experience great if not wonderful changes; and if such changes do result, I apprehend that they are brought about, not entirely alone because of fresh water evaporation from the new lake, but also and very considerably because of the attendant chlorine evaporation, that has its source in the immense salt 